\title{
AS RELAÇÕES ENTRE O ENSINO MÉDIO E A EDUCAÇÃO SUPERIOR NO BRASIL: PROFISSIONALIZAÇÃO E PRIVATIZAÇÃO
}

\author{
JoÃO DOS REIS SILVA JÚNIOR* \\ CARLOS LUCENA** \\ LUCIANA RODRIGUES FERREIRA***
}

\begin{abstract}
RESUMO: A proposta do artigo é contribuir para o entendimento da mudança que se põe ao ensino médio e sua relação com a educação superior, tendo por hipótese a crescente profissionalização e privatização do campo educacional, ao mesmo tempo a ampliação e consolidação das dualidades: esferas profissional e propedêutica, e, esferas pública e privada. Esta hipótese funda-se na racionalidade que presidiu tal processo de mudança nos meios institucionais para a concretização desta racionalidade na prática educacional cotidiana, bem como na alteração da natureza do trabalho do professor no contexto do trânsito do Regime de Acumulação Monopolista para o Regime de Acumulação Financeira.
\end{abstract}

Palavras-chave: Acumulação financeira. Reforma do Estado. Universidade pública. Ensino médio.

\section{RELATIONSHIPS BETWEEN HIGH SCHOOL AND HIGHER EDUCATION IN \\ BRAZIL: PROFESSIONALIZATION AND PRIVATIZATION}

ABSTRACT: This paper helps understanding the changes faced by high school and its relationship to higher education It assumes that the professionalization and privatization of the educational field are growing. At the same time, two dualities expand and consolidate: academic-pedagogical vs. professional, and public vs. private. This hypothesis is based on the rationality that has presided over this process of change in the institutional environment to concretize it in the everyday educational practice as well as on the changing nature of teachers' work in the context of a transition from a Monopolist Accumulation Regime to a Financial Accumulation Regime.

Key words: Financial Accumulation. State reform. Public university. High school.

* $\quad$ Doutor em Educação e professor do Departamento de Educação e do Programa de Pós-Graduação em Educação da Universidade Federal de São Carlos (UFSCAR). E-mail: joaodosreissilvajr@gmail. com

** Doutor em Educação e professor da Faculdade de Educação e do Programa de Pós-Graduação em Educação da Universidade Federal de Uberlândia (Ufu). E-mail: carloslucena@centershop.com.br

*** Doutoranda em Educação no Programa de Pós-Graduação em Educação da Universidade Federal de São Carlos (UFSCAR). E-mail: lucianarofer@gmail.com 


\section{LES RELATIONS ENTRE ENSEIGNEMENT SECONDAIRE ET ENSEIGNEMENT} SUPÉRIEUR: PROFESSIONNALISATION ET PRIVATIZATION

RÉSUMÉ: Cet article cherche à contribuer à la compréhension des changements qui semblent affecter le lycée et ses rapports à l'enseignement supérieur. Il part de l'hypothèse de ce que la professionnalisation et la privatisation augmentent dans le champ de l'éducation et que les dualités professionnel $\mathrm{x}$ propédeutique et public $\mathrm{x}$ privé s'étendent et se consolident. Cette hypothèse se base sur la rationalité ayant présidé au processus de changement et qui s'est concrétisée dans la pratique éducative quotidienne, ainsi que sur la modification de la nature du travail des professeurs dans le cadre d'une transition d'un régime d'accumulation monopoliste vers un régime d'accumulation financière.

Mots-clés: Accumulation financière. Réforme de l'État. Université publique. L'enseignement secondaire.

\section{Introdução}

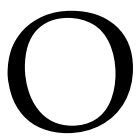

s resultados, eficiência e objetivos do ensino médio e superior no Brasil são questionados por parcela significativa da sociedade nas últimas décadas. Para alguns, sua importância e pressupostos se apresentam nas suas perspectivas e possibilidades de resistência e emancipação; para outros, a educação consiste em um dos maiores entraves da sociedade movimentada pela financeirização do capitalismo. Na primeira concepção, está presente um conceito de criticidade transformadora da sociedade. Entre estes, estão os "Filhos de Rousseau" - Iluministas defensores do conhecimento humano como força mobilizante da sociedade - e as concepções educativas revolucionárias que entendem a educação como força motriz do capital da resistência e transformação social. Posição diversa possui a segunda concepção, baseada no continuísmo e na adaptação social. O processo de "globalização" relacionado às mudanças tecnológicas fortaleceria as economias e as condições de vida da população mundial, ainda que empiricamente não tenhamos lido isto nos jornais. As iniciativas referentes a esse movimento impulsionam o capital a elevar sua reprodução na forma variável, reinventando, para isso, formas sofisticadas de exploração do trabalho. A pedagogia das competências, o "estar empregável" e o discurso da empregabilidade têm aí a sua gênese: formar trabalhadores aptos à multifunção e adequados ao pensamento e interesses empresariais. Assim entendemos que a educação vai se profissionalizando. Este é nosso entendimento inicial da categoria profissionalização.

A nossa preocupação, neste breve artigo, é problematizar os projetos em disputa manifestos na formulação das políticas educacionais brasileiras que influenciam as relações entre a educação superior e o ensino médio. Parece-nos que o percurso mais adequado para esse fim seja tomar a educação como ponto de partida. 


\section{Alguns indicadores sobre a profissionalização e a privatização do ensino médio}

O Brasil possui cerca de 16 milhões de analfabetos com 15 anos ou mais e 30 milhões de analfabetos funcionais (Hentges, 2011). Estes dados expressam uma grave e estrutural situação impulsionando governos a tomar medidas paliativas e imediatistas como o Programa Nacional de Integração da Educação Profissional e a Educação Básica na Modalidade de Educação de Jovens e Adultos (PROEJA) no âmbito nacional e diversos programas locais de aceleração da aprendizagem.

O Censo Escolar de 2010 demonstrou que o Brasil conta com 194.939 escolas de educação básica. Nelas estão matriculados 51.549 .889 alunos, sendo 85,3\% em escolas públicas e 14,7\% em escolas particulares. Os dados relativos ao ensino médio e profissionalizante são apresentados na tabela a seguir:

\section{Tabela 1}

Número de matrículas no ensino médio, normal/magistério, educação de jovens e adultos (EJA) e profissionalizante, por região (2009)

\begin{tabular}{|l|r|r|c|c|c|c|}
\hline REGIÃO & $\begin{array}{c}\text { Total do } \\
\text { Ensino } \\
\text { Médio }\end{array}$ & $\begin{array}{c}\text { Normal/ } \\
\text { Magistério }\end{array}$ & EJA & $\begin{array}{c}\text { Profissional } \\
\text { Integrado }\end{array}$ & $\begin{array}{c}\text { Profissional } \\
\text { Concomitante } \\
\text { e Subseqüente }\end{array}$ & $\begin{array}{c}\text { Profissionalizante } \\
\text { PJA+ } \\
\text { do Total Ensino } \\
\text { Médio }\end{array}$ \\
\hline Norte & 723.760 & 985 & 138.520 & 11.043 & 41.635 & 26,42 \\
\hline Nordeste & 2.512 .783 & 93.829 & 326.890 & 73.028 & 88.738 & 19,45 \\
\hline Sudeste & 3.356 .293 & 52.800 & 779.947 & 50.275 & 517.776 & 40,16 \\
\hline Sul & 1.134 .602 & 45.965 & 188.824 & 33.668 & 171.316 & 34,71 \\
\hline $\begin{array}{l}\text { Centro- } \\
\text { Oeste }\end{array}$ & 609.722 & 956 & 132.627 & 7.817 & 41.649 & 29,86 \\
\hline TOTAL & $\mathbf{8 . 3 3 7 . 1 6 0}$ & $\mathbf{1 9 4 . 5 3 5}$ & $\mathbf{1 . 5 6 6 . 8 0 8}$ & $\mathbf{1 7 5 . 8 3 1}$ & $\mathbf{8 6 1 . 1 1 4}$ & $\mathbf{3 1 , 2 3}$ \\
\hline
\end{tabular}

Fonte: INEP (2010b).

* Inclui matrículas na EJA presencial médio, semipresencial médio e integrado à educação profissional no ensino médio.

Algumas questões merecem destaque. Primeiramente, o número significativo de matriculados na EJA, superior a um milhão de alunos em 2009. Isso representa não somente uma corrida para a formação aligeirada, mas, sobretudo, uma estratégia política presente no atual regime de acumulação, visando integrar políticas públicas para preencher lacunas sociais de inclusão, carências educacionais, direito à cidadania, entre outras. ${ }^{1} \mathrm{O}$ segundo destaque refere-se ao 
estímulo financeiro às empresas contratantes e à execução realizada por Organizações Não Governamentais (oNG), Organizações da Sociedade Civil de Interesse Público (oscip) e empresas do Terceiro Setor. Na modalidade de ensino especialmente desenvolvida para pessoas fora da idade regular, a EJA ocupa um espaço representativo na educação: de modo geral, o país apresentou 4.234.956 matrículas no ano de 2010, sendo 2.846 .104 (67\%) no ensino fundamental e 1.388 .852 (33\%) no ensino médio. A maior parte dos alunos da EJA está matriculada na rede pública de ensino, 89,3\% (INEP, 2010a).

O terceiro aspecto refere-se à educação profissional. Quando observamos o número de matrícula integrada ao ensino médio, ele parece não representar um número significativo (175.831 mil). Entretanto, ao somarmos com as matrículas de alunos que estão nesta modalidade de forma concomitante ou subsequente $(861.114$ mil), chegamos ao total de 1.036 .945 matrículas, que, somado às da EJA, representa $31,23 \%$ de todas as matrículas deste nível no referido ano. Ao analisar estes percentuais por região (última coluna da Tabela 1), é possível verificar as variações regionais. A região Nordeste apresenta o menor percentual (com 19,45\%) e a região Sudeste com mais de $40 \%$ de suas matrículas vinculadas ao ensino profissionalizante. Vale ressaltar que 56,5\% das matrículas do ensino profissional são oferecidas por instituições privadas, 31,3\% por instituições estaduais, 9,6\% por instituições federais e 2,5\% por instituições municipais (INEP, 2010a). Entretanto, mais de 70\% destas matrículas nas instituições privadas estão articuladas ao ensino profissional subsequente, ou seja, alunos que já concluíram o ensino médio. O ensino técnico de nível médio concomitante (por opção do aluno) e integrado (na mesma instituição) obtém maior expressão nas instituições públicas, principalmente a articulação integrada com $76 \%$ das matrículas.

Conforme os dados de Pesquisa Nacional por Amostra de Domicílios de 2009 (PNAD, 2010) com referência à relação entre a escolarização e a renda familiar, as regiões Norte e Nordeste apresentam os piores índices em termos de defasagem educacional de alunos pobres com idade entre 15 e 17 anos. Em termos do percentual de alunos que cursam o ensino médio, a região Norte apresenta 39,1\% e a Nordeste, $39,2 \%$. Estes índices somados e quando comparados à região Sudeste, com 60,5\% para a mesma faixa etária, mostram a desigualdade entre os estados da Federação brasileira que se encontram acima e abaixo da linha do Equador.

De acordo com o Instituto Brasileiro de Geografia e Estatística (IBGE), a distribuição percentual - de estudantes de 18 a 24 anos - se faz da seguinte forma: 10,7\% no ensino fundamental; 34,9\% no ensino médio e 42,8\% no superior (IBGE, 2008). Estes índices são problematizados, levando em consideração a existência de profundas desigualdades regionais produzidas pelo desenvolvimento histórico do capitalismo brasileiro. 
Em 2008, o IBGE realizou levantamento do número de alunos e seu respectivo poder aquisitivo no ensino médio no Brasil. A rede pública possuía 6.935 .000 alunos no ensino médio e a rede particular, 1.121 .000 alunos. A tabela a seguir demonstra a distribuição percentual por quinto de rendimento familiar per capita dos alunos do ensino médio no país, nas redes pública e privada.

\section{Tabela 2}

Distribuição percentual de alunos do ensino médio por renda per capita, redes públicas e privadas - Brasil (2008)

\begin{tabular}{|c|c|c|c|}
\hline \multicolumn{2}{|c|}{ Rede Pública } & \multicolumn{2}{c|}{ Rede Privada } \\
\hline $\begin{array}{c}\text { Quinto de rendimento } \\
\text { familiar per capita }\end{array}$ & $\begin{array}{c}\text { Índice } \\
\text { Percentual }\end{array}$ & $\begin{array}{c}\text { Quinto de rendimento } \\
\text { familiar per capita }\end{array}$ & $\begin{array}{c}\text { Índice } \\
\text { Percentual }\end{array}$ \\
\hline 1 quinto & 19,7 & 1 quinto & 2,3 \\
\hline 2 quintos & 25,1 & 2 quintos & 5,1 \\
\hline 3 quintos & 24,5 & 3 quintos & 9,9 \\
\hline 4 quintos & 20,4 & 4 quintos & 24,8 \\
\hline 5 quintos & 10,4 & 5 quintos & 58,0 \\
\hline
\end{tabular}

Fonte: IBGE (2008).

Esta tabela demonstra a presença de alunos com menor poder aquisitivo nas escolas públicas de ensino médio no Brasil, implicando ações governamentais, em razão da necessidade de inclusão social imposta pela estrutura do capitalismo brasileiro, sem romper com a lógica da reprodução social.

Ao analisar o perfil socioeconômico dos estudantes das universidades federais brasileiras, disposto no relatório de pesquisa encomendado pela Associação Nacional dos Dirigentes das Instituições Federais de Ensino Superior (ANDIFEs), em julho de 2011, notam-se as disparidades econômico-sociais e de acesso a estas universidades nas diferentes regiões:

\section{Tabela 3}

Distribuição percentual dos estudantes das universidades federais por classes econômicas ${ }^{2}$

\begin{tabular}{|l|c|c|c|}
\hline \multicolumn{1}{|c|}{ Região } & A1/A2 (\%) & B1/B2 (\%) & C, D e E (\%) \\
\hline Norte & 6,32 & 24,61 & 69,07 \\
\hline Nordeste & 12,16 & 35,82 & 52,02 \\
\hline Sudeste & 18,34 & 47,24 & 34,42 \\
\hline Sul & 16,78 & 49,38 & 33,84 \\
\hline Centro-Oeste & 22,06 & 42,02 & 35,92 \\
\hline NACIONAL & $\mathbf{1 5 , 2 6}$ & $\mathbf{4 1 , 0 7}$ & $\mathbf{4 3 , 6 7}$ \\
\hline
\end{tabular}

Fonte: ANDIFES (2011, p. 20). 
Observa-se no decorrer do relatório uma grande ênfase sobre o percentual de estudantes de classes mais baixas nas universidades federais, especialmente oriundos de escola pública. Entretanto, pode-se observar que o percentual nacional de $43,6 \%$ para as classes C, D e E não representa a realidade regional. Isso se comprova tomando como referência os dados do PNAD de 2010, apresentados anteriormente, demonstrando a grande defasagem educacional de jovens ( 15 a 17 anos) nas regiões Norte e Nordeste, em comparação com a região Sudeste. Nas demais regiões, as classes B1 e B2 representam a maioria.

Ao investigar a instituição em que os estudantes cursaram o ensino médio (escola pública ou privada), destaca-se a região Norte com $71 \%$ de estudantes egressos de escolas públicas, o que ratifica o acesso diferencial das classes $C$, D e E nesta região. O Sudeste, por sua vez, apresenta o maior percentual (50,5\%) de alunos oriundos de escolas particulares. Outro dado importante está relacionado às modalidades de ensino médio dos estudantes das federais. A maioria $(87,4 \%)$ cursou o ensino médio padrão (regular). Este percentual oscila de $95 \%$ a $100 \%$ quando observadas as classes A1 e A2 no Norte, Nordeste, Sul e Centro-Oeste (exceto Sudeste, com 88 e 93\%, respectivamente). Em seguida, tem-se o ensino técnico $(8,2 \%)$, magistério $(1,83 \%)$, EJA $(2,16 \%)$ e outros $(0,4 \%)$. Estes dados nos permitem constatar que são poucos os alunos oriundos do ensino técnico/profissional que ingressam nas universidades federais, ingressando, isso sim, de forma significativa, em profissões modestas no mercado de trabalho. Além disso, a lógica profissional privatizante está imbricada no ensino propedêutico (médio padrão), enraizada nas orientações internacionais de mercado, nos documentos oficiais (habilidades e competências dos Parâmetros Curriculares Nacionais), nos programas de governo e no direcionamento das políticas de Estado, que é pressionada de forma estrutural para reorganizar-se, com o objetivo de preparar um novo trabalhador no que se refere ao seu saber técnico e à sua sociabilidade.

\section{A matriz cepalina da profissionalização do ensino médio no Brasil}

Em documento recente, chamado de $O$ novo cenário laboral latino-americano: regulação, proteção e políticas ativas nos mercados de trabalho, a Comisión Económica para América Latina y Caribe (CEPAL, 2009) recomenda aos países desta região um novo movimento para a consolidação das forças produtivas. Trata-se da combinação de mercados de trabalho flexíveis e formação contínua para o trabalhador, especialmente com o aumento da perspectiva da vida média desta população. O sistema educativo teria que qualificar continuamente os trabalhadores para se adaptar às mudanças no processo produtivo. Aqui se encontra o centro a partir do qual a racionalidade das políticas para o ensino médio se faz, e estes elementos se originam no movimento maior da economia planetária. 
No documento existe a "sugestão" do modelo flexicurity, adotado também no Brasil, baseado em políticas ativas compensatórias para as exigências de um mercado de trabalho flexível, com a formação técnico-profissionalizante por meio de instituições privadas, com estímulo do fundo público. É assim que entendem os intelectuais da cepal e os formuladores de políticas educacionais de emprego e renda no Brasil:

\begin{abstract}
A busca pelo modelo de flexicurity nos leva ao elemento do triângulo dourado relativo ao sistema de políticas ativas compensatórias na presença de um mercado de trabalho flexível. O Brasil já as pratica, mas elas padecem de alguns males. O volume de recursos ainda é relativamente diminuto para o tamanho da força de trabalho brasileira, o rol de políticas é bastante diminuto, resumindo-se a praticamente três (intermediação da mão de obra, treinamento vocacional e programas de geração de emprego e renda) e, o pior de todos os males, estas políticas são pouco integradas entre si, e não são articuladas com o seguro-desemprego. (...) as políticas ativas brasileiras desfrutam de pouca eficiência, possuem baixa eficácia e não promovem a equidade como deveriam. Além disso, elas não promovem a "ativação" necessária no âmbito de cada uma, facilitando o agravamento do comportamento negativo de certos aspectos do mercado de trabalho. (CEPAL, 2009, p. 107)
\end{abstract}

Para a CEPAL, o Brasil precisa melhorar o atendimento dos trabalhadores informais, investindo em recursos humanos e informática como forma de suprir as carências inerentes ao analfabetismo e o baixo nível escolar de boa parte da força de trabalho que não consegue se adaptar às transformações e às novas exigências produtivas. "Parte substancial deste problema deve ser resolvida por políticas de médio e longo prazo, na esfera do Ministério da Educação, com parte de um amplo programa educacional para colocar a população brasileira em níveis de padrão educacionais observados em nações de estágio mais avançado" (idem, ibid.). A melhoria da qualificação dos trabalhadores se relaciona com a eficiência do sistema nacional de capacitação e treinamento profissional oferecido. “(...) no caso brasileiro o desafio deste setor é maior, seja porque os números são dramáticos, seja porque as dificuldades de educação básica da força de trabalho, nos moldes acima mencionados, têm ficado aquém da expectativa, para não dizer que não existem, seja sob a ótica da quantidade, ou então da qualidade" (ibid.).

Aqui é bom relembrar que parte do sucesso do treinamento vocacional está condicionado à sua articulação com outras políticas ativas ou passivas. Em especial, a integração entre o treinamento e a intermediação da mão de obra certamente melhora as chances de sucesso da recolocação do desempregado, e a articulação entre o treinamento e o programa de seguro-desemprego tende a ter o mesmo impacto, ambos com impactos positivos sobre a redução da taxa de desemprego aberto. A implantação de um modelo de flexicurity, com as características brasileiras, onde a maior flexibilidade no mercado de trabalho tivesse como contrapartida um sistema mais sólido de proteção social, deveria contar com adesão oficial do governo, que o transformasse numa "razão de Estado", sendo colocado como uma prioridade nacional fundamental, e assim deveria ser tratada. (CEPAL, op. cit., p. 107-108; grifos nossos) 
O Programa Nacional de Acesso à Escola Técnica (PRONATEC), ainda em debate no governo Dilma Rousseff, exemplifica esta afirmação. O PRONATEc tem como objetivo ampliar o número de estudantes matriculados em cursos técnicos, suprir a carência de trabalhadores no mercado de trabalho e elevar a empregabilidade dos jovens trabalhadores. Sua meta é a formação de três milhões de profissionais até 2014. O projeto é voltado a capacitar jovens de ensino médio e trabalhadores que utilizaram o seguro desemprego e famílias cadastradas no programa Bolsa Família. O Programa baseia-se em seis iniciativas, assim descritas: Bolsa-Formação; fIEs Técnico; Brasil Profissionalizado; E-TEC Brasil; Expansão da Rede Federal de Educação Profissional e Tecnológica; Vagas Gratuitas no Sistema S. O PRONATEc 2011 visa a estruturação do ensino técnico no Brasil, elevando o número de vagas na educação profissional por intermédio dos institutos de ensino federal, escolas públicas e órgãos do Sistema $\mathrm{S}$ de ensino - SESC, SENAC, SESI, SENAI e SENAT. O Programa visa a romper a carência de trabalhadores qualificados em setores produtivos, contribuindo com o crescimento econômico do país. Em que pese a fase preliminar em que se encontra o referido projeto, o que não nos possibilita análises conclusivas sobre sua efetividade, seus pressupostos filosóficos não são neutros. Eles nos indicam a racionalidade presente nas políticas públicas para o ensino médio: a lógica da profissionalização, da privatização e da política focal, baseada, no âmbito das suas formulações, na mesma matriz teórica, política e ideológica que orienta o aparelho estatal desde a Reforma do Estado em 1995.

Chamam-nos a atenção as iniciativas governamentais voltadas ao financiamento de setores da iniciativa privada, como se elas já não possuíssem suas próprias estruturas administrativas e formativas. Iniciativas como as do PRONATEC demonstram a vontade política de suprir a profissionalização, tendo neste setor uma plataforma estratégica, mesmo que o país tenha a maior parte de sua população mais carente nas escolas públicas, para as quais - reivindicam sindicatos, associações científicas e educadores - deveriam rumar os recursos do fundo público. Vale dizer que num governo popular e democrático esta vocação política é contraditória, somente compreensível diante de análise mais ampla, quando se percebe a predominância financeira. O PRONATEc desconsidera o desemprego como manifestação especificamente concreta da financeirização do capital mundializada, posto que esta predominância, ao intensificar o trabalho humano e produzir a precarização das relações de trabalho, produz ao mesmo tempo o desemprego estrutural.

O ensino superior no Brasil é movido por racionalidade similar ao ensino médio. A educação superior, especialmente a pública, sofre consequências intensas das reformas educacionais, na estrutura do ensino, no acesso, nas relações de trabalho, na produtividade acadêmica, na aproximação do capital (parceria público-privada e indução de pesquisa aplicada) ${ }^{3}$ ao lado da certificação em massa; além disso, as universidades públicas passam ainda por um processo de recolocação estratégica para criarem 
condições de financiamento e se transformarem em agências executoras de políticas do Estado. O contexto atual da educação superior compromete a qualidade do ensino e o perfil profissional dos "futuros" trabalhadores e professores da educação básica, haja vista as peculiaridades e carências docentes, principalmente no ensino médio.

Na educação superior, os professores dos cursos de formação de educadores veem-se às voltas com classes numerosas e com a pressão patronal voltada à aprovação do maior número possível de estudantes. Acrescenta-se que a grande maioria dos cursos que voluntariamente aderiram ao Plano de Apoio à Reestruturação e Expansão da Universidade federal (REUNI), por dependerem exclusivamente do fundo público para sua manutenção, são compostos pelas licenciaturas. Destaca-se ainda que há norma no REUNi que induz a retenção de menos de $10 \%$ dos alunos deste Plano.

Uma ampla divisão entre instituições públicas, privadas e comunitárias confessionais forma o complexo educativo do ensino superior no Brasil. A tabela 4, a seguir, referente aos cursos de Ciências da Educação e formação de professores, permite diagnosticar o oferecimento de vagas no Brasil na área de Educação, no ano de 2009.

$\mathrm{Na}$ análise dos dados apresentados, dois pontos se destacam. Primeiro: comparando a oferta pública e a privada, observa-se a significativa diferença na oferta de cursos, com as instituições privadas na frente nas seis subáreas da Educação. Dentre estas, destacam-se as Ciências da Educação, em que se concentram os cursos na área de gestão e funcionamento da Educação, com a oferta de 70\% dos cursos da área. Com isso é possível inferir que as instituições privadas são as maiores responsáveis pela formação da maior parte do corpo diretivo e pedagógico das escolas brasileiras, públicas ou privadas. Outra subárea de significativa predominância privada é a de formação de professor de matérias específicas, com 51,5\%. De modo concreto, isso significa a formação das diversas licenciaturas destinadas em essência à formação básica e média também no âmbito privado (presencial e a distância). Isso se coaduna com os incentivos fiscais para as instituições privadas, como o Programa de Universidade para Todos (PROUNI) e o financiamento público para os estudantes dado pelo Fundo de Financiamento ao estudante do ensino Superior (FIES), ambos com preferência para os alunos de licenciatura nas diversas formações específicas.

O segundo ponto refere-se à proporção de oferta dos cursos da educação com o total de cursos da educação superior, apresentados na tabela em sua última linha, com os percentuais proporcionais pelo número total de cursos ofertados (primeira linha). Pode-se inferir que $46,2 \%$ dos cursos oferecidos pelas instituições públicas estaduais são da área da Educação; em seguida seguem a instância municipal (30,8\%) e a federal (24,2\%). A dimensão profissionalizante encontra-se em cada conteúdo de todas as seis subáreas em que o Instituto Nacional de Educação Anísio Teixeira (INEP) divide a educação superior. 


\section{Tabela 4}

Cursos de graduação presencial por subáreas - Educação: Brasil (2009)

\begin{tabular}{|c|c|c|c|c|c|c|}
\hline \multirow[b]{2}{*}{$\begin{array}{l}\text { Educação } \\
\text { (subáreas) }\end{array}$} & \multicolumn{3}{|c|}{ Pública } & \multicolumn{2}{|c|}{ Privada } & \multirow[b]{2}{*}{ Total } \\
\hline & Federal & & Municipal & Particular & $\begin{array}{c}\text { Comunitárias } \\
\mathrm{e} \\
\text { Confessionais }\end{array}$ & \\
\hline $\begin{array}{l}\text { Total geral de Cursos } \\
\text { Presencial } \\
\text { (todas as áreas) }\end{array}$ & 4.368 & 3.126 & 734 & 15.049 & 4.550 & 27.827 \\
\hline Ciências da Educação & 181 & 263 & 39 & 880 & 238 & 1.601 \\
\hline $\begin{array}{l}\text { Formação de professor da } \\
\text { educação básica }\end{array}$ & 68 & 164 & 17 & 182 & 64 & 495 \\
\hline $\begin{array}{l}\text { Formação de professor de } \\
\text { disciplinas profissionais }\end{array}$ & 142 & 122 & 35 & 300 & 145 & 744 \\
\hline $\begin{array}{l}\text { Formação de professor de } \\
\text { educação infantil }\end{array}$ & 10 & 10 & 3 & 24 & 11 & 58 \\
\hline $\begin{array}{l}\text { Formação de professor de } \\
\text { matérias específicas }\end{array}$ & 656 & 884 & 132 & 1.206 & 573 & 3.451 \\
\hline $\begin{array}{l}\text { Formação de professor } \\
\text { e Ciências da Educação } \\
\text { (cursos gerais) }\end{array}$ & 2 & 1 & 0 & 3 & 3 & 9 \\
\hline Total geral da Educação & 1.059 & 1.444 & 226 & 2.595 & 1.034 & 6.358 \\
\hline $\begin{array}{l}\text { Percentual da Educação } \\
\text { sobre o Total geral de } \\
\text { cursos }\end{array}$ & 24,2 & 46,2 & 30,8 & 17,2 & 22,7 & 22,8 \\
\hline
\end{tabular}

Fonte: INEP (2010c)

As pesquisas e reivindicações centrais em relação à educação superior são a democratização do acesso a este nível de ensino. O governo federal segue em continuidade com o PROUNI, sempre na direção privatista. No setor público esboçou-se um processo de expansão da educação superior, predominantemente pelo REUNI, por cursos oferecidos por meio da educação a distância e da Universidade Aberta do Brasil (UAB). Em geral, a maior parte destas vagas é oferecida nos cursos de pedagogia e de licenciaturas. A estas modalidades e ao setor privado a formação do trabalhador professor da educação básica foi direcionada e nestas esferas é realizada.

Nas universidades públicas brasileiras, a maior parte dos alunos com vagas em cursos voltados para a carreira docente é oriunda do ensino médio público, possuindo menos acesso à cultura em razão de suas condições de vida. O ensino superior privado dentro desta modalidade apresenta condições precárias para o exercício da docência 
e, consequentemente, para o processo formativo educacional. A carência expressa na formação de professores põe-se contra a própria profissão, legitimando, através dos discursos conservadores, o ensino médio privado como única alternativa para o acesso a outras profissões, entendidas como possibilidade concreta de ascensão social.

No relatório A atratividade da profissão docente, produzido pela Fundação Carlos Chagas e coordenado pela professora Bernadete Gatti, evidencia-se o que apresentamos. Em entrevista concedida, Gatti (2010) afirma que:

O Brasil já experimenta as consequências do baixo interesse pela docência. Segundo estimativa do Instituto Nacional de Estudos e Pesquisas Educacionais Anísio Teixeira (INEP), apenas no ensino médio e nas séries finais do ensino fundamental o déficit de professores com formação adequada à área que lecionam chega a 710 mil. E não se trata de falta de vagas. "A queda de procura tem sido imensa. Entre 2001 e 2006, houve o crescimento de $65 \%$ no número de cursos de licenciatura. As matrículas, porém, se expandiram apenas 39\%", afirma Bernardete Gatti, pesquisadora da Fundação Carlos Chagas e supervisora do estudo. De acordo com dados do Censo da Educação Superior de 2009, o índice de vagas ociosas chega a 55\% do total oferecido em cursos de Pedagogia e de formação de professores.

Na continuidade de sua entrevista com base na referida pesquisa afirma:

O perfil é bastante semelhante ao dos atuais estudantes de Pedagogia. De acordo com o Exame Nacional de Desempenho dos Estudantes (ENADE) de Pedagogia, 80\% dos alunos cursaram o ensino médio em escola pública e $92 \%$ são mulheres. Além disso, metade vem de famílias cujos pais têm no máximo a $4^{\underline{a}}$ série, $75 \%$ trabalham durante a faculdade e $45 \%$ declararam conhecimento praticamente nulo de inglês. E o mais alarmante: segundo estudo da consultora Paula Louzano, 30\% dos futuros professores são recrutados entre os alunos com piores notas no ensino médio. O panorama desanimador é resumido por Cláudia, aluna de escola pública em Feira de Santana, a 119 quilômetros de Salvador: "Hoje em dia, quase ninguém sonha em ser professor. Nossos pais não querem que sejamos professores, mas querem que existam bons professores. Assim, fica difícil". (Idem, ibid.)

Essas considerações se explicam quando relacionadas às transformações na sociedade capitalista expressas pelo movimento da financeirização do capital. Chama a atenção a dificuldade de ascensão social relacionada ao desprestígio que afeta a profissão "professor" no Brasil. A educação na história nacional significou a possibilidade concreta de transição e prestígio de classe. A história do Brasil mostra inúmeros exemplos de profissionais que se autointitularam "doutores", tendo cursado, no máximo, a graduação. A quebra desse processo configurou o professor como um exemplo daquilo que os alunos não gostariam de ser: um profissional com baixa remuneração e precárias condições de trabalho. O movimento e as contradições expressos na história negaram as concepções liberais defensoras de que o acesso a postos dominantes na sociedade era uma questão de eficiência, demonstrando que a ascensão às classes dominantes é limitada. 
Contudo, em um cenário de disputas em torno de visões de mundo antagônicas, o pensamento conservador, relacionado ao processo monetarista, respondeu a essa questão desvinculando a ascensão social de um processo coletivo, respondendo aos sonhos de inclusão da classe média, ao materializar discursos e justificativas ideológicas expressas pelo projeto neoliberal. O sucesso e a conquista de um emprego são percebidos como um processo individual, manifesto por competências também individuais materializadas. A teoria das competências e da empregabilidade é o argumento utilizado por instituições de ensino privado, tanto em nível médio, como superior, como justificativa de sua expansão e existência. Essa visão, em um cenário monetarista, é corroborada por uma concepção de competência governamental, apresentando-se como neutra, quando na realidade é classista e baseia-se na expansão incontrolada do capital.

Estudando a expansão da educação superior, Sguissardi (2008), com enfoque no setor privado, nos mostra com clareza este movimento de formação de grupos predominantemente educacionais, parafraseando Serfati (1998). O que está em jogo é a parcela do valor financeiro que será abocanhada pelo grupo que detém agora o capital acionário das unidades educacionais de ensino médio ou superior. Em geral, são fundos de pensão ou fundos mutuais nos dois níveis, afirma Sguissardi (2008, p. 1003):

\footnotetext{
Entretanto, essas estimativas quanto aos números e percentuais de IEs privado/mercantis e de matrículas nessas instituições poderão ser muito rapidamente ultrapassadas pela realidade. Os noticiários da imprensa corporativa ou comercial têm cada vez mais chamado a atenção para um fenômeno que antes era próprio do mercado financeiro, industrial e comercial: a presença de grandes fundos de investimento [capital portador de juros] no chamado mercado educacional do país, como já ocorre em alguns outros países do centro e da periferia global. Na edição 101 da revista Ensino Superior, do SEMESP, 9 de fevereiro de 2007, anunciava-se em manchete "A consolidação do mercado". Completava-se: "Até 2010, 60\% das instituições de ensino superior brasileiras com menos de 500 alunos devem ser extintas, diz especialista" (Gorgulho, 2007). O número de matrículas dobraria nesse período, chegando-se a 8 milhões, mas com grandes mudanças. Das 1.100 IEs com menos de 500 alunos, cerca de $60 \%$ fechariam suas portas e seus alunos migrariam para outras instituições. As demais, cerca de $40 \%$, seriam absorvidas por outras mantenedoras ou por outros proprietários ou fundos de investimento. $\mathrm{O}$ setor vai se consolidar em uma economia de escala, em que grandes grupos oferecerão ensino superior barato, com uma qualidade razoável, prevê o consultor financeiro Renato de Souza Neto, ex-sócio da Paulo Renato Souza Consultores.
}

Esse processo se explica em um movimento econômico, político e social na sociedade. No regime de acumulação financeira, o capital monetário parece adquirir autonomia absoluta em relação à produção real do valor (primeiro ciclo de movimentação do capital). Trata-se do ápice do fetichismo da mercadoria dinheiro. Este cenário induz à real mudança no processo de trabalho, na indústria e na educação e impõe a referida matriz teórica, política e ideológica da reforma do aparelho do Estado. A 
educação se torna um espaço social estratégico para a produção do valor, financiada pelo fundo público (sua privatização) e para a necessária profissionalização, em razão da infinitésima diferença entre ciência e tecnologia e das inovações tecnológicas que são feitas quase em tempo real em todo o planeta. Neste regime, o aumento do valor faz-se pelo único meio, qual seja a diminuição de sua medida, com mediações: a necessária diminuição do tempo de trabalho necessário para a produção da mercadoria força de trabalho. A reengenharia, isto é, as novas formas de organização e do trabalho são possíveis graças às novas bases científicas e tecnológicas agregadas às máquinas e equipamentos e à gestão dos trabalhadores. Segundo Serfati (1998, p. 177), isto possibilitaria e coagiria a uma "baixa de custo em razão da reorganização dos processos de gestão [que não deveria] ser de $15 \%$ a $20 \%$, mas de $80 \%$ a $90 \% "$. Neste processo, o aparelho de Estado e a educação são exigidos de forma estrutural a ser reformados nesta direção, ao mesmo tempo em que, na condição de um serviço educacional realizado pela iniciativa privada, sofreriam as mesmas consequências dos demais processos produtores de valor. Ademais, posto que o Estado neoliberal atua com base no monetarismo e põe os títulos de sua dívida pública no mercado financeiro internacional, o aparelho estatal acaba por se tornar refém tanto do capital financeiro como das corporações transnacionais. E o capital financeiro tem nome e endereço, é de "carne, osso e cérebro", e sua ética orienta-se pela "ganância".

\section{Capital financeiro, reforma do Estado e educação no Brasil}

Na década de 1980, especialmente em seu início, a mundialização do Investimento Externo Direto (IED) sofreu significativo aumento. No entanto, para além dos aspectos quantitativos do IED na economia mundial, seus aspectos qualitativos parecem realmente colocá-lo no centro do regime de acumulação. Para Chesnais (1996), citando Henri Bourguinat, são quatro as principais razões:

\footnotetext{
Em primeiro lugar, diferentemente do comércio exterior, o IED "não tem uma natureza de liquidez imediata (...) ou diferida (...)". Não se reduz a uma transação pontual. Sua segunda característica é introduzir uma "dimensão intemporal" de grande importância, pois a "decisão de implantação dá origem a fluxos (produção, comércio, repatriação de lucros) que se estendem, necessariamente, por vários longos períodos". A terceira particularidade é "implicar transferências de direitos patrimoniais e, portanto, de poder econômico, sem medida comum à simples exportação". "Por último", diz Bourguinat, "existe um componente estratégico evidente na decisão de investimento da companhia. Não somente seu horizonte é sensivelmente mais amplo, como também as motivações subjacentes são muito ricas (...) a idéia de penetração, seja para depois esvaziar os concorrentes locais, seja para 'sugar' as tecnologias locais, [e a produção de conhecimento em lugares além da sede do grupo predominantemente industriall faz parte desse aspecto 'estratégico' do investimento direto e, geralmente, está inserido num processo complexo de tentar antecipar as ações e reações dos concorrentes". (Chesnais, 1996, p. 54; grifos do autor em itálico e nossos em negrito)
} 
A predominância financeira afeta as relações entre os ciclos de movimentação do capital, impondo formas muito diversas de organização e introdução de grupos predominantemente industriais ${ }^{4}$ (GPI) em novo lugar na economia mundial. A função financeira põe-se como aquela que exige maior produtividade e especialmente novas formas de organização do trabalho, com consequências para a intensificação do trabalho humano e de precarização das relações de trabalho em qualquer processo com potência de produção de valor. Inclui-se aí, portanto, a esfera educacional, quando ofertada por instituições privadas. Por outro lado, impõe ao Estado a produção de um ordenamento jurídico e de políticas públicas sob mesma orientação.

Nesse contexto de mundialização da economia, tendo como estratégia central a necessidade da produção do capital produtivo, mas, sobretudo as novas formas de obtenção de mais-valia por meio de inovações financeiras, o IED, nos moldes examinados por Chesnais e Bourguinat, emerge como centro de novo paradigma de empresa, com novas estruturas corporativas, novas formas organizativas e de gestão, assentadas em nova base produtiva, possibilitadas, neste último caso, pelas atuais tecnologias produzidas no âmbito da terceira revolução tecnológica. Portanto, impõe ao Estado o desenho de políticas para pesquisa nas universidades e para formação profissional impõe uma tarefa hercúlea, depois da adesão brasileira ao regime de produção financeira desde o início da década de 1990. Chesnais (op. cit.) afirma que há a emergência de um "novo estilo", em cujo centro encontra-se a estratégia tecnofinanceira realizada pelos Caixas Centralizados dos grupos predominantemente industriais, tendo como base especialmente o capital humano do GPI. Essas corporações mundiais, ou GPI, teriam em seu centro identitário a natureza e forma das relações que estabelece com outras empresas e instituições na esfera econômica e social e com as instituições republicanas, tendo o Estado como mediador.

Este movimento colocar-se-á para os processos de mudanças na esfera educacional, especialmente para o ensino médio e para a educação superior. A educação é afetada pela mundialização do capital, implicando mudanças em seus princípios expressos nos pressupostos formativos. O que percebemos é que, no caso da esfera educacional, sua especificidade tomou a forma de um processo educacional voltado para uma formação humana reducionista, predominantemente profissionalizante, realizada por intermédio de uma lógica profissionalizante e privatista. E, entre os níveis e modalidades mais atingidos, destaca-se o ensino médio e sua ambiguidade exógena à esfera pedagógica - profissional e propedêutica -, agora articulada com a contradição entre o público e o privado.

Essa formação de cunho individual assenta suas justificativas em uma crítica radical à centralidade do Estado, apontando como saída a instauração de um conjunto de relações expressas por inteligências coletivas - heterogêneas a diversificadas -, 
constituídas por indivíduos atuando no mercado. Sendo a equidade o pressuposto de funcionamento do mercado, os seres humanos a ele vinculados são entendidos como únicos e diferenciados, com potencialidades distintas. A materialização, no Brasil, deste processo faz-se concreta no início da década de 1990, quando Fernando Henrique Cardoso assumiu cargos de relevância no aparelho de Estado.

Paulani e Oliveira (2007), ao tratar das relações entre centro e periferia da economia mundial, deixam claro o novo lugar e estatuto do Estado brasileiro:

(...) O conceito de uma periferia depende da existência do Estado-nação. Entretanto a existência de uma nação consiste em substantivo deveras tênue na atualidade. Contudo, o aparelho Estado permanece intacto como instrumento para governar uma força de trabalho e, simultaneamente, relega os seus direitos a plano secundário, justificando o aumento da taxa de exploração. Inversamente, concede isenções, subsídios e incentivos com o objetivo de aumentar a lucratividade do capital. A constante necessidade de atrair o capital mundializado na sua principal forma [o IED] é apenas um lado deste movimento. Seu outro lado consiste na transformação do aparelho de Estado em um instrumento de valorização do capital financeiro. (Paulani \& Oliveira, 2007, p. 15-16; tradução livre e grifos nossos)

Consequentemente, a reforma do aparelho do Estado que teve início em 1995 carrega consigo esta racionalidade (a matriz aqui já referida) trazida pela predominância financeira. Nele tem origem um novo paradigma em que as políticas se orientam pela mesma matriz teórica, política e ideológica do Estado já reformado. Esta matriz embasou as reformas das demais instituições republicanas, especificamente, no caso em tela da reforma educacional no Brasil. Destaca-se ainda que:

Foi também o governo de Cardoso que deu o primeiro passo para garantir que os direitos dos credores financeiros fossem sempre honrados, em relação às dívidas do setor público ou privados. No auge da crise que levou à desvalorização do real em janeiro de 1999, o governo negociou com o FMI e reafirmou seus compromissos já assumidos e o resultado concreto desta negociação foi a Lei de Responsabilidade Fiscal, que entrou em vigor em maio de 2000. O objetivo da Lei de Responsabilidade Fiscal (LRF) foi estabelecer uma hierarquia dos gastos públicos, que colocaria em primeiro lugar os direitos indiscutíveis do titular de ativos financeiros emitidos pelo Estado, em detrimento de alocação de fundos para propostas distributivas e investimentos públicos. A “austeridade fiscal" que presidiria a LRF impôs ao governo fazer impiedosas reduções nos investimentos em programas sociais, em deferência aos interesses dos credores nacionais e internacionais. (Idem, ibid., p. 21; tradução livre dos autores)

\section{Conclusão}

A análise das relações entre o ensino médio e a educação superior no Brasil constituiu-se em notório desafio. Debater a educação, tomando como referência as especificidades do capitalismo brasileiro manifesto, entre outros fatores, nas 
disparidades entre o norte e o sul do país, propiciou base para uma análise crítica do processo em curso. As relações entre o ensino médio e o nível superior e a rígida divisão entre ensino propedêutico e profissional fundamentaram o desenvolvimento de um conceito de profissionalização composto pela crítica à homogeneização da força de trabalho em atendimento aos interesses do mercado.

No primeiro aspecto demonstrado anteriormente, as políticas educacionais nacionais acabam por referendar uma rígida divisão de classes no que se refere à formação educacional. Às classes mais favorecidas, uma educação voltada à pesquisa aplicada e ao saber científico. Às classes trabalhadoras, uma educação de cunho profissional, atendendo às demandas do mercado de trabalho. No segundo aspecto, especialmente no que se refere à formação dos trabalhadores, o ensino médio acaba por exemplificar iniciativas para esse fim. O PROEJA, O PRONATEC, as diretrizes e parâmetros curriculares atendem às recomendações de organismos internacionais, tal qual demonstrado através das recomendações da CEPAL, bem como às reivindicações empresariais da qualificação de trabalhadores para o exercício da função, em um cenário de constantes transformações tecnológicas na produção industrial.

As políticas compensatórias ganharam eco, legitimadas pelo alto índice de analfabetos funcionais e pela histórica baixa escolaridade brasileira. A qualificação profissional é utilizada como mecanismo para responder aos anseios de inclusão social dos trabalhadores no Brasil. O entendimento do desemprego como um processo conjuntural e não estrutural acabou por legitimar discursos cuja aparência é transformadora, mas a essência, conservadora. Ao mesmo tempo, essas políticas compensatórias acabaram por materializar um processo de privatização da educação no Brasil, sustentado pelo discurso da competência do mercado e pela ineficiência do Estado.

Essas políticas compensatórias, mesmo estando entre elas o PRONATEC, aprovado na Comissão de Educação do Congresso, mas ainda em caráter de implementação, coloca-nos algumas questões. Em primeiro lugar, a efetividade do entendimento do desemprego como um fenômeno conjuntural. Conseguirão as políticas suprir os aspectos estruturais do desemprego através da qualificação profissional? Em segundo lugar, destaca-se a precarização da formação e exercício da profissão dos professores no ensino médio. Como superar essa relação, visto que, em função das precárias condições de trabalho, poucos querem ser professores? Por último, a economia e a educação. O que nos parece, apesar dos discursos otimistas, é que a dívida brasileira ainda está em escala crescente e o futuro é incerto. Será apenas a qualificação como um fenômeno doméstico a responsável pela inclusão social, ou isso se refere a um processo internacional? O debate está lançado... 


\section{Notas}

1. Temos como exemplo o Programa Nacional de Estímulo ao Primeiro Emprego para os Jovens (PNPE) (Lei n. 10.748/2003, substituída pela Lei n. 11.692/2008), chamado apenas de PRojovem, destinado aos jovens de 15 a 29 anos, com o objetivo de "promover sua reintegração ao processo educacional, sua qualificação profissional e seu desenvolvimento humano" (Brasil, 2008, p. 1).

2. A descrição de classe é considerada pela pesquisa da ANDIFEs (2011, p. 20) como a renda média familiar bruta pelas faixas de pontuação estabelecidas pela Associação Brasileira das Empresas de Pesquisa (ABEP) para classificação econômica: A1 (R\$ 11.480); A2 (R\$ 8.295); B1 (R\$ 4.754); B2 (R \$ 2.656); C1 (1.459); C2 (R\$ 962); D (R\$ 680); e E (R\$ 415).

3. Os cursos que produzem alta tecnologia conseguem recursos para sua manutenção por meio das parcerias público-privadas, da Lei de Inovação Tecnológica, da Lei do Bem, entre outras, apesar da omissão política do Estado que, a sua maneira, se reforma segundo o novo regime de acumulação.

4. Os grupos predominantemente industriais consistem num "conjunto formado por uma sociedademãe (chamada de holding do grupo) e as sociedades filiais que estão sob o seu controle. Assim, a sociedade-mãe é acima de tudo um centro de decisão financeira; enquanto as sociedades sob seu controle não passam, na maior parte das vezes, de sociedades exploradoras. O papel essencial de uma sociedade-mãe é a arbitragem permanente das participações financeiras que ela detém, em função da rentabilidade dos capitais envolvidos. É a função de arbitragem da sociedade-mãe que confere ao grupo o seu caráter financeiro" (Morin apud Serfati, 1998, p. 143).

\section{Referências}

ASSOCIAÇÃO NACIONAL DOS DIRIGENTES DAS INSTITUIÇÕES FEDERAIS DE ENSINO SUPERIOR (ANDIFES). Perfil socioeconômico e cultural dos estudantes de graduação das universidades federais brasileiras. In: Fórum Nacional de Pró-Reitores de Assuntos Comunitários e Estudantis (FONAPRACE). Brasília, DF: ANDIFEs, 2011.

BRASIL. Lei n. 11.692, de 10 de junho de 2008. Dispõe sobre o Programa Nacional de Inclusão de Jovens - Projovem. Diário Oficial da União, Brasília, DF, 11 jun. 2008. Disponível em: <http://www.planalto.gov.br/ccivil>. Acesso em: 3 jun. 2011.

BRASIL. Ministério da Educação. Instituto Nacional de Estudos e Pesquisas Educacionais (INEP). Censo escolar 2010: resumo técnico; versão preliminar. Brasília, DF: INEP, 2010a. Disponível em: <http://portal.inep.gov.br/basica-censo>. Acesso em: 16 jun. 2011.

BRASIL. Ministério da Educação. Instituto Nacional de Estudos e Pesquisas Educacionais (INEP). Sinopse Estatística da Educação Básica 2009. Brasília, DF: INEP, 2010b. Disponível em: <http://portal.inep.gov.br/basica-censo-escolar-sinopse-sinopse>. Acesso em: 5 fev. 2011.

BRASIL. Ministério da Educação. Instituto Nacional de Estudos e Pesquisas Educacionais (INEP). Sinopse Estatística da Educação Superior 2009. Brasília, DF: INEP, 2010c. Disponível em: <http://portal.inep.gov.br/superior-censosuperior-sinopse>. Acesso em: 5 fev. 2011. 
BRASIL. Ministério da Educação. Programa Nacional de Acesso ao Ensino Técnico e Emprego (PRONATEC). Qualificação técnica e profissional para trabalhadores e alunos do ensino médio. Disponível em: <http://pronatecportal.mec.gov.br/>. Acesso em: 3 mar. 2011.

CHESNAIS, F. A mundialização do capital. São Paulo: Xamã, 1996.

COMISSÃO ECONOMICA PARA A AMÉRICA LATINA E O CARIBE (CEPAL). O novo cenário laboral latino-americano: regulação, proteção e políticas ativas nos mercados de trabalho. Santiago: CEPAL, 2009.

GATTI, B. Entrevista. In: Educar para crescer. São Paulo: Abril, 2010. s/p. Disponível em: $<$ http://educarparacrescer.abril.com.br/politica-publica/professor-profissao-desvalorizada-534523.shtml\#>. Acesso em: 5 maio 2011.

HENTGES, G.L. Educação no Brasil hoje: a possibilidade de uma formação de qualidade. 5 maio 2011. Disponível em: <http://www.webartigos.com/articles $>$. Acesso em: 11 maio 2011.

INSTITUTO BRASILEIRO DE GEOGRAFIA E ESTATÍSTICA (IBGE). Sintese de Indicadores Sociais: uma análise das condições de vida da população brasileira. Brasília, DF: IGBE, 2008.

PAULANI, L.M.; OLIVEIRA, F. Financialization and barbarism: a perspective from Brazil. In: Veltemeyer, H.; Bowles P. (Org.). National perspectives on globalization. Hampshire: Palgrave Macmillan, 2007. p. 13-27.

PNAD: Pesquisa Nacional por Amostra de Domicílios 2009. Brasília, DF: Ministério da Fazenda, 2010. Disponível em: <http://www.fazenda.gov.br/spe/publicacoes/ conjuntura/bancodeslides/IE $\% 202010 \% 2009 \% 2014 \% 20-\% 20$ PNAD $\% 202009$.pdf $>$. Acesso em: 3 mar. 2011.

SERFATI, C. O papel dos grupos predominantemente industriais na financeirização da economia. In: Chesnaıs, F. A mundialização financeira. São Paulo: Xamã, 1998. p. 141-181.

SGUISSARDI, V. Modelo de expansão da educação superior no Brasil: predomínio privado/mercantil e desafios para a regulação e a formação universitária. Educação $\mathcal{E}$ Sociedade, Campinas, v. 29, n. 105, p. 991-1.022, set./dez. 2008.

Recebido em 17 de junho de 2011.

Aprovado em 4 de setembro de 2011. 